Article

\title{
Carbone Monoxide (CO) Detection Device Based on the Nickel Antimonate Oxide and a DC Electronic Circuit
}

\author{
José Trinidad Guillen Bonilla ${ }^{1,2, *(\mathbb{0})}$, Héctor Guillén Bonilla ${ }^{3}$, \\ Verónica María Rodríguez Betancourtt ${ }^{4}$, Antonio Casillas Zamora ${ }^{3}$, \\ Jorge Alberto Ramírez Ortega ${ }^{3}$, Lorenzo Gildo Ortiz ${ }^{5}$, María Eugenia Sánchez Morales ${ }^{6}$, \\ Oscar Blanco Alonso ${ }^{5}$ and Alex Guillén Bonilla ${ }^{7, *}$ \\ 1 Departamento de Electrónica, Centro Universitario de Ciencias Exactas e Ingenierías (C.U.C.E.I.), \\ Universidad de Guadalajara, Blvd. M. García Barragán 1421, Guadalajara 44410, Jalisco, Mexico \\ 2 Departamento de Matemáticas, Centro Universitario de Ciencias Exactas e Ingenierías (C.U.C.E.I.), \\ Universidad de Guadalajara, Blvd. M. García Barragán 1421, Guadalajara 44410, Jalisco, Mexico \\ 3 Departamento de Ingeniería de Proyectos, Centro Universitario de Ciencias Exactas e Ingenierías (C.U.C.E.I.), \\ Universidad de Guadalajara, Blvd. M. García Barragán 1421, Guadalajara 44410, Jalisco, Mexico \\ 4 Departamento de Química, Centro Universitario de Ciencias Exactas e Ingenierías (C.U.C.E.I.), \\ Universidad de Guadalajara, Blvd. M. García Barragán 1421, Guadalajara 44410, Jalisco, Mexico \\ 5 Departamento de Física, Centro Universitario de Ciencias Exactas e Ingenierías (C.U.C.E.I.), \\ Universidad de Guadalajara, Blvd. M. García Barragán 1421, Guadalajara 44410, Jalisco, Mexico \\ 6 Departamento de Ciencias Tecnológicas, Centro Universitario de la Ciénega (CUCienéga), \\ Universidad de Guadalajara, Av. Universidad No. 1115, LindaVista, Ocotlán C.P. 47810, Jalisco, Mexico \\ 7 Departamento de Ciencias Computacionales e Ingenierías, Centro Universitario de los Valles (CUValles), \\ Universidad de Guadalajara, Carretera Guadalajara-Ameca Km. 45.5, Ameca 46600, Jalisco, Mexico \\ * Correspondence: trinidad.guillen@academicos.udg.mx (J.T.G.B.); alexguillenbonilla@gmail.com (A.G.B.); \\ Tel.: +52-(375)-7580-500 (ext. 47417) (A.G.B.)
}

Received: 17 August 2019; Accepted: 9 September 2019; Published: 11 September 2019

Featured Application: Our CO detection device finds practical safety applications where there is possible leakage of carbon monoxide by combustion and it is desirable to detect it. For example: cracked heat exchangers, locked chimneys, boiler safety systems, inadequate installation of boilers, heating devices without exhaust gas ducts and inverted fireplace effect.

Abstract: Carbon monoxide (CO) is very toxic to health. CO gas can cause intoxication and even death when the concentration is high or there are long exposure times. To detect atmospheres with $\mathrm{CO}$ gas concentration detectors are placed. In this work, a novel $\mathrm{CO}$ detection device was proposed and applied for $\mathrm{CO}$ detection. For its implementation, four stages were developed: Synthesis of nickel antimonite $\left(\mathrm{NiSb}_{2} \mathrm{O}_{6}\right)$ oxide powders, physical characterization of $\mathrm{NiSb}_{2} \mathrm{O}_{6}$ powders, Pellet fabrication and sensitivity test in $\mathrm{CO}$ atmospheres and electronic circuit implementation where signal adaptation and signal amplification were considered. Experimentally, a chemical sensor was built and characterized, its signal adaptation circuit was implemented and also it was proved using $\mathrm{CO}$ concentrations from 1 to $300 \mathrm{ppm}$ with the operating temperatures of 100,200 , and $300{ }^{\circ} \mathrm{C}$. Its optimal operation was at $300{ }^{\circ} \mathrm{C}$. From the experimental results, the $\mathrm{CO}$ detection device had excellent functionality because the chemical sensor based on the nickel antimonite oxide had high sensitivity and good electrical response, whereas the DC electronic circuit had good performance.

Keywords: a novel $\mathrm{CO}$ detection device; $\mathrm{CO}$ detection; nickel antimonite oxide; chemical sensor; electronic circuit implementation; high sensitivity 


\section{Introduction}

Air pollution produced by the emission of gases such as $\mathrm{CO}, \mathrm{CO}_{2}, \mathrm{CH}_{4}, \mathrm{C}_{3} \mathrm{H}_{8}, \mathrm{SO}_{2}$, and $\mathrm{H}_{2} \mathrm{~S}$, among others [1-3], has caused a substantial decrease in the quality of life of humans and other species. This emission of toxic gases into the atmosphere of large cities by industries and internal combustion engines is considered to be the main cause of diseases due to respiratory and cardiovascular nature, not to mention the greenhouse effect and the ecological and environmental imbalance they also provoke [4-9]. To mitigate the damage, it is necessary to have better control of the concentrations of harmful gases. For this purpose, different binary semiconductor oxides, such as $\mathrm{SnO}_{2}, \mathrm{Mn}_{2} \mathrm{O}_{3}$, $\mathrm{GeO}_{2}, \mathrm{MoO}_{3}$, and $\mathrm{Nb}_{2} \mathrm{O}_{5}$, among others, have been investigated in the past [10-12]. It has been recently suggested that ternary semiconductor oxides are strong candidates to be applied as gas sensors [13-16]. Among these materials, we can find the perovskite (e.g., $\mathrm{LaFeO}_{3}$ ) [17] and the spinel (e.g., $\mathrm{CuFe}_{2} \mathrm{O}_{4}$ ) type structures [18]. On the other hand, other studies report that semiconductor oxides with trirutile-type structure possess interesting detection properties since they are chemically stable and can operate at different temperature ranges (mainly between 200 and $350{ }^{\circ} \mathrm{C}$ ) [19]. The trirutile-type oxides most commonly employed for this application are $\mathrm{CuSb}_{2} \mathrm{O}_{6}$ [20], $\mathrm{NiSb}_{2} \mathrm{O}_{6}$ [21], $\mathrm{MgSb}_{2} \mathrm{O}_{6}$ [22], $\mathrm{ZnSb}_{2} \mathrm{O}_{6}$ [23], and more recently $\mathrm{CoSb}_{2} \mathrm{O}_{6}$ [24].

It has been established that the high efficiency and good response of semiconductor materials for detecting toxic gases are mainly due to their morphology and porosity, and the nanometric size of the particles $[19,22]$. To obtain this type of microstructural features, different synthesis routes have been used in the past, like the solid-state reaction, hydrothermal, coprecipitation, and sol-gel processes [25-27]. On the other hand, the colloidal synthesis method has been increasingly employed because through this process it is possible to obtain porous surfaces, diverse morphologies (nanoparticles, nanowires, nanorods, and nanobelts), and particle sizes less than $100 \mathrm{~nm}$ [22-24].

The $\mathrm{NiSb}_{2} \mathrm{O}_{6}$ oxide was applied for the Liquefied Petroleum Gas (LPG) and Carbon dioxide $\left(\mathrm{CO}_{2}\right)$ detection. The oxide was synthetized using a via sol-gel spin coating method. In the experimental work, the electrical resistance changed when the $\mathrm{NiSb}_{2} \mathrm{O}_{6}$ oxide was exposed to LPG and $\mathrm{CO}_{2}$. The measurement concentrations were into the interval of 1000 until $5000 \mathrm{ppm}$ [21]. In reference [28], the authors proposed a chemical detector based on $\mathrm{NiSb}_{2} \mathrm{O}_{6}$ oxide. The $\mathrm{NiSb}_{2} \mathrm{O}_{6}$ powders were synthetized using the microwave-assisted colloidal method. In the experiments, propane $\left(\mathrm{C}_{3} \mathrm{H}_{8}\right)$ and Carbon monoxide (CO) were detected, the concentrations were between 0 and $300 \mathrm{ppm}$, the operation temperatures were from 100 to $300^{\circ} \mathrm{C}$ and the maximum sensitivity was approximately 2.14 (to $300^{\circ} \mathrm{C}$ ). On the other hand, using the microwave-assisted wet chemical method, the chemical sensor based on the $\mathrm{NiSb}_{2} \mathrm{O}_{6}$ oxide was better. The sensitivity was increased from 2.1 to 14.1 (to $300{ }^{\circ} \mathrm{C}$ ) [29]. Again, in the experimental work, $\mathrm{C}_{3} \mathrm{H}_{8}$ and $\mathrm{CO}$ were used and the concentrations were between 0 and $300 \mathrm{ppm}$. However, to our knowledge, the signal adaptation was not proposed for the chemical sensor based on the $\mathrm{NiSb}_{2} \mathrm{O}_{6}$ oxide. In this work, the nickel antimonite $\left(\mathrm{NiSb}_{2} \mathrm{O}_{6}\right)$ oxide was synthetized, characterized and applied as a chemical sensor for the carbon monoxide detection. Experimentally, its signal adaptation was implemented using a DC electronic circuit which was based on a Wheatstone bridge and operational amplifiers. The prototype device can detect $\mathrm{CO}$ concentration into the interval of 1 until $50 \mathrm{ppm}$ and its optimal operating temperature was $300^{\circ} \mathrm{C}$. Our $\mathrm{CO}$ detection device has easy implementation, low cost, high sensitivity, good functionality, and also many practical safety applications.

\section{CO Device Implementation}

To build the $\mathrm{CO}$ detection device four stages were required: Synthesis of $\mathrm{NiSb}_{2} \mathrm{O}_{6}$ oxide powders, physical characterization of $\mathrm{NiSb}_{2} \mathrm{O}_{6}$ powders, Pellet fabrication and sensitivity test in $\mathrm{CO}$ atmospheres, Signal adaptation and signal amplification where the DC electronic circuit was supplied with a DC supply voltage. Figure 1 shows the four stages. Each stage is described in the next sections. 
Materials

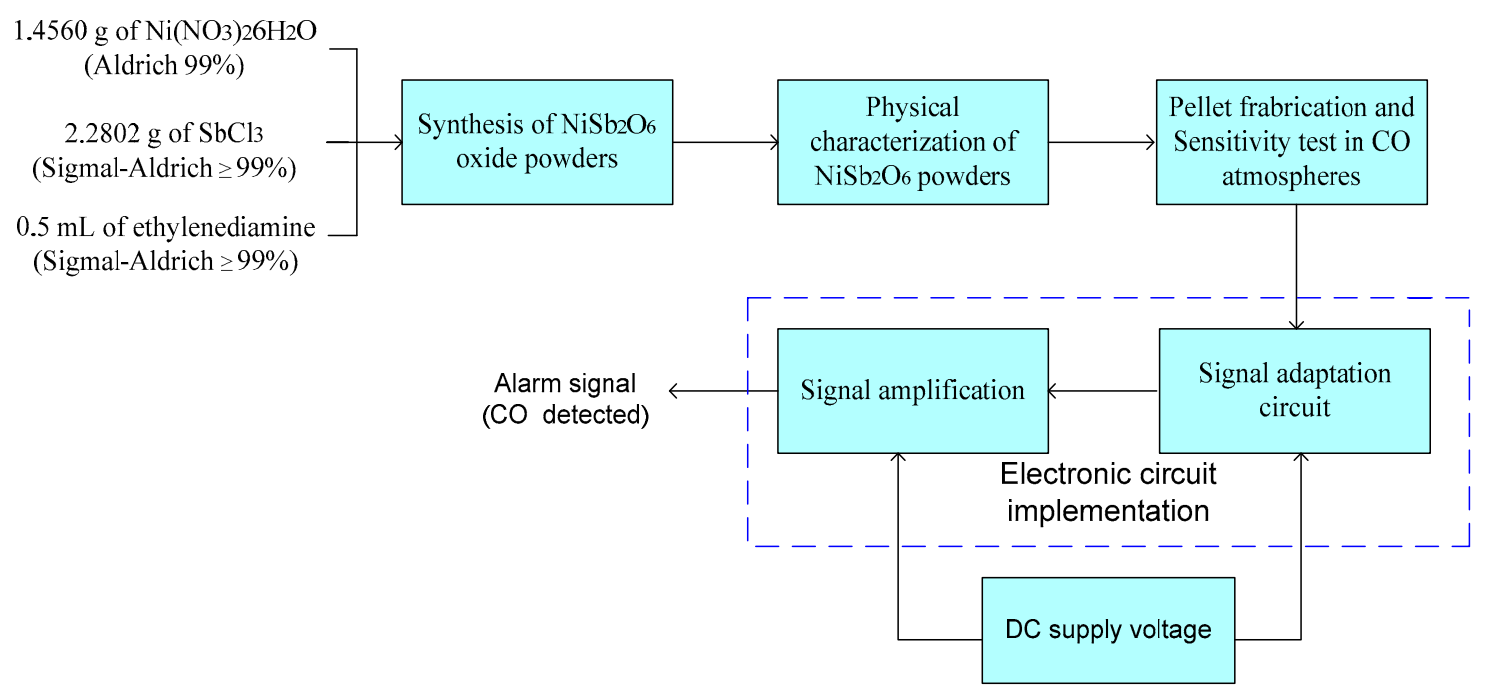

Figure 1. Stages required for the $\mathrm{CO}$ detection device.

\subsection{Synthesis of $\mathrm{NiSb}_{2} \mathrm{O}_{6}$ Oxide Powders}

The production of the trirutile oxide powders was done through a microwave-assisted wet-chemistry process [28-30] using $1.4560 \mathrm{~g}$ of Ni(NO$\left.)_{2}\right)_{2} \cdot 6 \mathrm{H}_{2} \mathrm{O}$ (Aldrich, 99\%), $2.2802 \mathrm{~g}$ of $\mathrm{SbCl}_{3}$ (Sigma-Aldrich $\geq 99 \%$ ), and $0.5 \mathrm{~mL}$ of ethylenediamine (Sigma-Aldrich $\geq 99 \%$ ). The reagents were diluted in $5 \mathrm{~mL}$ of absolute ethyl alcohol (Jalmek) and then left stirring for $20 \mathrm{~min}$ at room temperature. The solutions of nickel nitrate and antimony chloride were added dropwise to the ethylenediamine solution. The resulting mixture produced a green precipitate, which was kept under stirring at room temperature for $24 \mathrm{~h}$ at a speed of $300 \mathrm{rpm}$. Evaporation of the solvent was done by applying seventeen 90-s exposures to a low power $(140 \mathrm{~W})$ microwave radiation using a domestic microwave oven (General Electric, model JES796WK). The energy absorbed by the solution was estimated at $\sim 214.2 \mathrm{~kJ}$. Subsequently, using a programmable Novatech muffle, two thermal treatments at a rate of $100{ }^{\circ} \mathrm{C} / \mathrm{h}$ in the air were applied to the precursor material: A drying at $200^{\circ} \mathrm{C}$ for $8 \mathrm{~h}$ and calcination at $800^{\circ} \mathrm{C}$ for $5 \mathrm{~h}$.

\subsection{Physical Characterization of $\mathrm{NiSb}_{2} \mathrm{O}_{6}$ Powders}

The characterization of the crystalline phase of the trirutile oxide $\mathrm{NiSb}_{2} \mathrm{O}_{6}$ was carried out using powder X-ray diffraction (XRD). The analysis was done using Panalytical Empyrean equipment with $\mathrm{CuK} \alpha$ radiation and a wavelength of $1.546 \AA$. The diffractograms were obtained at a $2 \theta$ scan from $10^{\circ}$ to $60^{\circ}$, applying $0.026^{\circ}$-steps at a rate of $30 \mathrm{~s}$ per step. The porosity, morphology, and particle size of the material dried at $800^{\circ} \mathrm{C}$ were analyzed using a scanning electron-microscope (SEM, JEOL JSM-6390LV) in modality of high vacuum and secondary electron emission.

\subsection{Pellet Fabrication and Sensitivity Test in CO Atmospheres}

The sensitivity tests consisted of measuring the changes in the $\mathrm{NiSb}_{2} \mathrm{O}_{6}$ pellets' electrical resistance at different operating temperatures $\left(100,200\right.$, and $\left.300^{\circ} \mathrm{C}\right)$ and different concentrations of $\mathrm{CO}(0,5,50$, 100,200 , and $300 \mathrm{ppm}$ ). The pellets of the material were elaborated using $0.3 \mathrm{~g}$ of the powder dried at $800^{\circ} \mathrm{C}$ and compacting it by means of a hydraulic press (Simplex Ital Equip-25 Tons) applying 10 tons for $60 \mathrm{~s}$. The dimensions of the pellets were of $0.5 \mathrm{~mm}$ in thickness and $12 \mathrm{~mm}$ in diameter. Prior to the gas detection measurements, two ohmic contacts of colloidal silver paint (Alfa Aesar, 99\%) were placed on the surface of the pellets. Afterward, the $\mathrm{NiSb}_{2} \mathrm{O}_{6}$ pellets were placed inside a measuring chamber (Chambers) with a vacuum capacity of $10^{-3}$ torr. The partial pressure of the gases inside the 
chamber was controlled using a TM20 Leybold detector. The electrical resistance measurements were made using a Keithley 2001 multimeter. Finally, the response (sensitivity) was estimated according to the formula $[20,22,24]: S=\left(G_{G}-G_{O}\right) / G_{O}$, where, $G_{G}$ y $G_{O}$ are the pellets' conductances (1/electric resistance) in the test gas ( $\mathrm{CO})$ and air, respectively.

\subsection{Electronic Circuit}

For the signal adaptation of our chemical sensor, an economic electronic circuit was proposed. The electronic circuit consists of a Wheatstone bridge, a differential amplifier and an operational amplifier (Op-amp) comparator have been applied. The electronic circuit has been supplied by Vcc1 and Vcc sources. The Wheatstone bridge consists of four resistors: $R_{1}=R_{2}$ are precision resistors, $R_{S}$ is the resistance of the chemical sensor and $R_{x}$ is a variable resistance for calibration. The differential amplifier consists of an operational amplifier and four precision resistors, $R_{3}, R_{4}, R_{5}$, and $R_{6}$. Finally, the Op-am comparator will be an operational amplifier. Basically, the signal adaptation circuit requires two stages: calibration and detection.

\subsubsection{Signal Adaptation Circuit (Wheatstone Bridge Calibration)}

In the calibration stage, the chemical sensor is installed in atmospheres with no presence of $\mathrm{CO}$, the sensor terminals are connected to the Wheatstone bridge according to Figure 2 and the Wheatstone bridge is calibrated by varying $R_{x}$ until the following condition is met:

$$
V_{A B}=V_{A}-V_{B}=0
$$

and then the next condition $V_{A}=V_{B}$ is true.

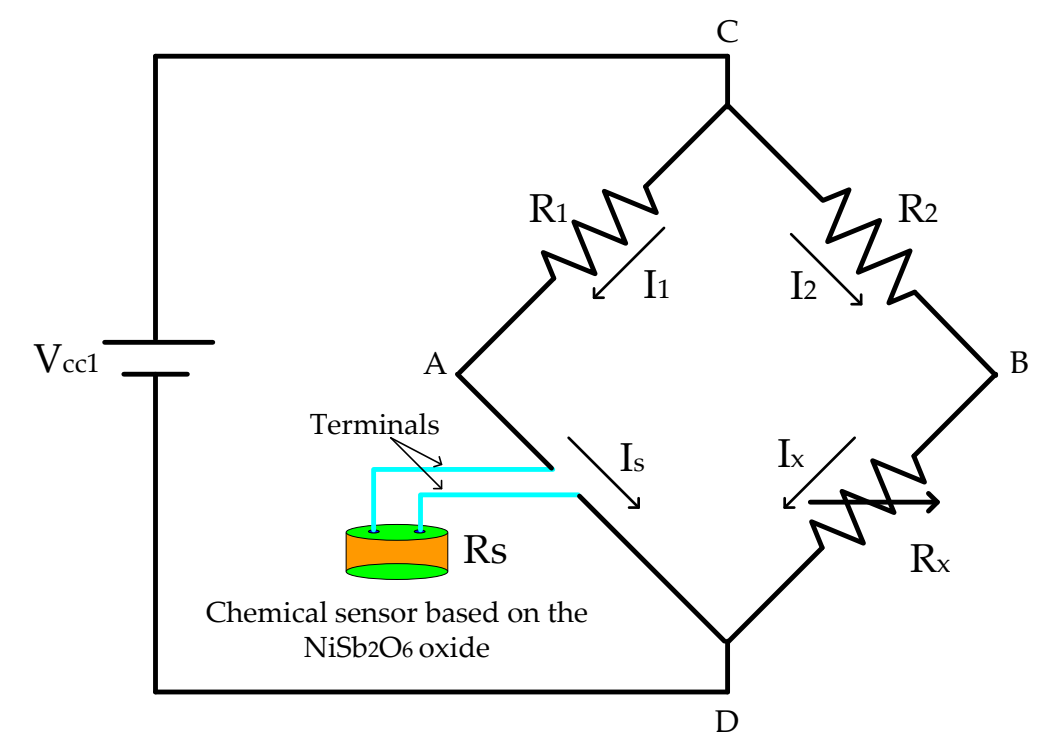

Figure 2. The conditions required for the calibration of a Wheatstone bridge.

Based on the Equation (1) and Figure 2, we will have

$$
V_{A}=V_{B} \rightarrow \frac{V_{C A}}{V_{A D}}=\frac{V_{C B}}{V_{B D}}
$$

Observing Figure 2, $V_{C A}, V_{A D}, V_{C B}$, and $V_{B D}$ are defined as

$$
\frac{V_{C A}}{V_{A D}}=\frac{I_{1} R_{1}}{I_{S} R_{s}} \text { and } \frac{V_{C B}}{V_{B D}}=\frac{I_{2} R_{2}}{I_{x} R_{x}}
$$


Since the Wheatstone bridge is calibrated, then $I_{1}=I_{S}$ and $I_{2}=I_{x}$ are true and as a consequence, Equation (2) can express through

$$
V_{A}=V_{B} \rightarrow \frac{R_{1}}{R_{s}}=\frac{R_{2}}{R_{x}}
$$

From Equation (4), the resistance $R_{x}$ can be determined by

$$
R_{x}=R_{s} \frac{R_{2}}{R_{1}}
$$

When Equation (5) is satisfied, then the Whetstone bridge is completely calibrated.

\subsubsection{Detection Circuit (Signal Adaptation + Signal Amplification)}

In the detection stage, the following five steps are carried out: (a) The sensor terminals are connected to the Wheatstone bridge according to Figure 3, (b) The chemical sensor is exposed to the carbon monoxide atmosphere placing the electronic circuit in a secure area, (c) When the chemical sensor detects the presence of $\mathrm{CO}$, the Wheatstone bridge has an imbalance and the following conditions are met:

$$
V_{A} \neq V_{B} \text { and } V_{A}<V_{B}
$$

(d) Both voltages $V_{A}$ and $V_{B}$ have been compared applying a differential amplifier based on the operational amplifier, see Figure 3.

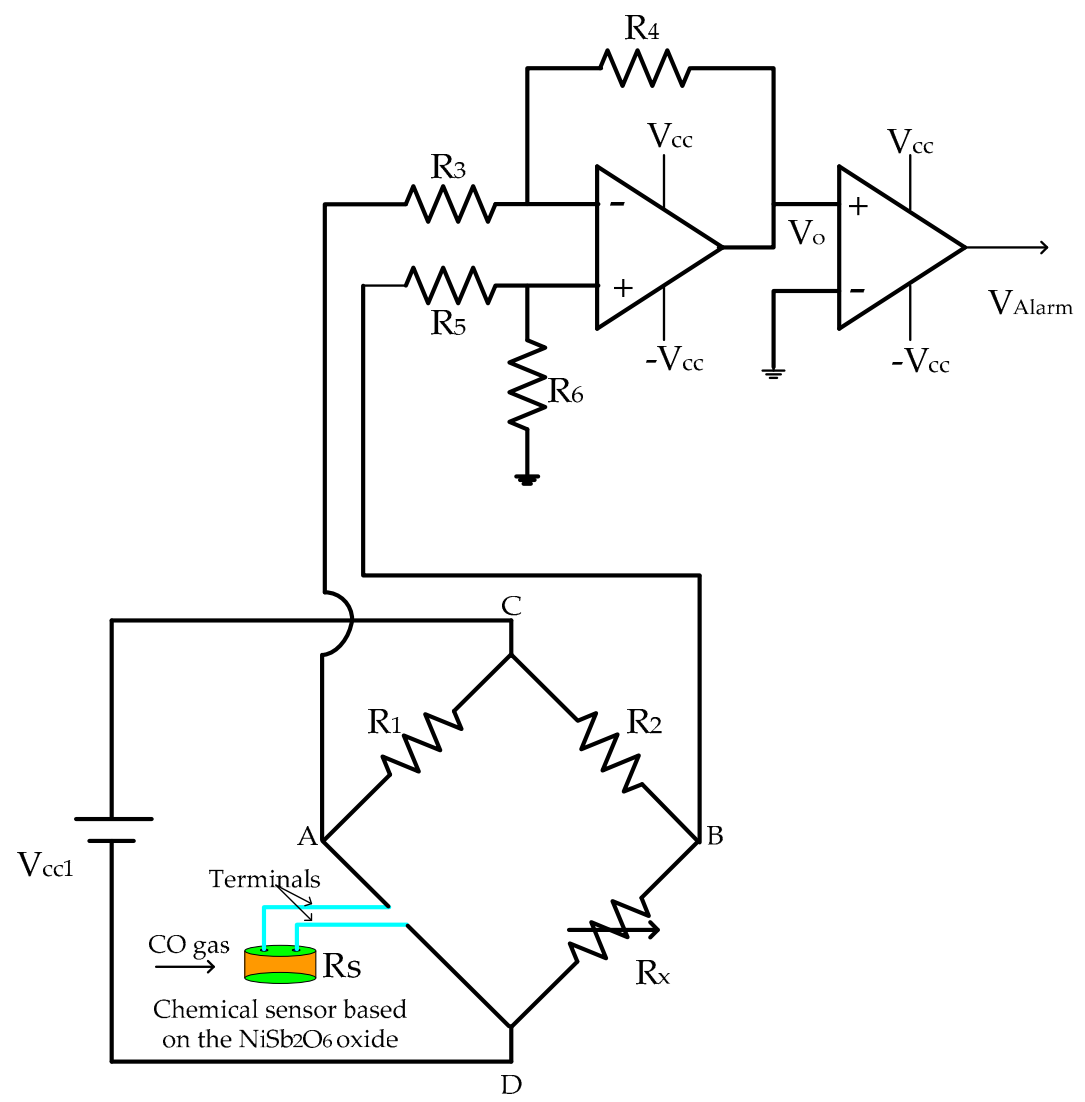

Figure 3. Electronic circuit proposed for the CO detection.

From Figure 3, the differential amplifier satisfies

$$
V_{o}=V_{B}\left(\frac{R_{6}}{R_{6}+R_{5}}\right)\left(1+\frac{R_{4}}{R_{3}}\right)-V_{A} \frac{R_{4}}{R_{3}}
$$


If $R_{3}=R_{5}$ and $R_{4}=R_{6}$, Equation (7) takes the form

$$
V_{o}=A\left(V_{B}-V_{A}\right)
$$

where the amplification, $A=\frac{R_{4}}{R_{3}}=\frac{R_{6}}{R_{5}}$ is a factor and $V_{o}$ is an output voltage of our differential amplifier. Immediately, we impose the conditions $R_{3}=R_{4}$ and $R_{5}=R_{6}$. Then, the output voltage is the difference

$$
V_{o}=V_{B}-V_{A}
$$

(e) The voltage $V_{o}$ is applied as an input signal to the comparator circuit verifying that:

$$
V_{\text {Alarm }}=A_{o l} V_{o}
$$

where $V_{\text {Alarm }}$ is the alarm signal produced by the detection device and $A_{o l}$ is the gain of the operational amplifier in an open loop. Thus, the signal is amplified by the operational amplifier. According to Equation (10), the device will generate an alarm signal when the chemical sensor is exposed to carbon monoxide, $\mathrm{CO}$.

\section{Experimental Results}

\subsection{XRD Analysis}

Figure 4 shows the diffractogram of the material obtained from the chemical reaction between the nickel nitrate and the antimony chloride, plus ethylenediamine, and calcined at $800^{\circ} \mathrm{C}$. In the XRD pattern, the characteristic peaks of $\mathrm{NiSb}_{2} \mathrm{O}_{6}$ located at points $2 \theta=19.23^{\circ}, 21.41^{\circ}, 27.15^{\circ}, 33.49^{\circ}, 34.99^{\circ}$, $38.77^{\circ}, 40.16^{\circ}, 43.63^{\circ}, 44.71^{\circ}, 53.21^{\circ}$, and $56.20^{\circ}$ can be clearly observed.

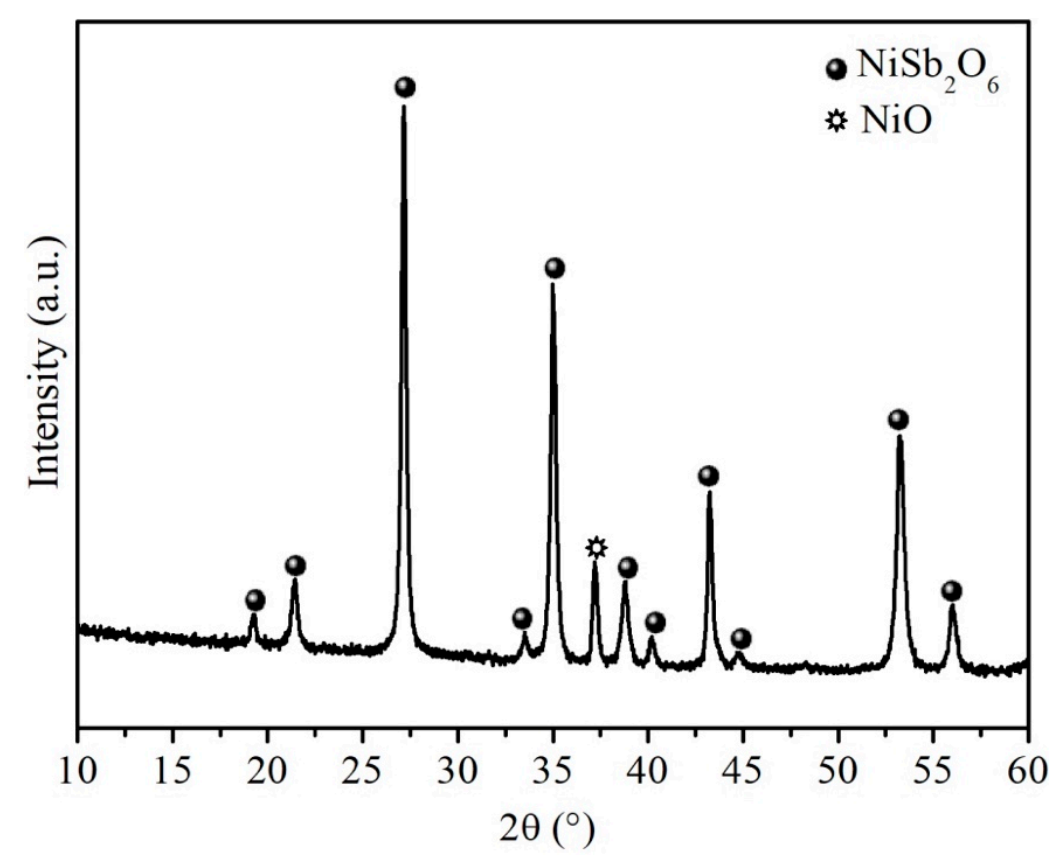

Figure 4. Diffractogram of the oxide $\mathrm{NiSb}_{2} \mathrm{O}_{6}$ obtained by calcination at $800{ }^{\circ} \mathrm{C}$ in air.

The main crystalline phase of the oxide was identified by means of the PDF file No. 86-0110. According to this, the $\mathrm{NiSb}_{2} \mathrm{O}_{6}$ crystallized into a tetragonal structure with cell parameters $\mathrm{a}=\mathrm{b}=$ $4.641 \AA$ and $\mathrm{c}=9.219 \AA$, with spatial group $\mathrm{P} 42 / \mathrm{mnm}$ (136). It has been previously reported that the peaks of the oxide's main phase (see Figure 4) belong to the trirutile-type family of structures or the trirutile-type antimonates $[21,28]$. This characteristic is obtained by modifying the axis' c-direction of 
the rutile cell [31]. On the other hand, a small portion of inorganic material outside the main phase can be seen in the diffractogram. This reflection was located at point $2 \theta=37.1^{\circ}$ and corresponds to a secondary phase of $\mathrm{NiO}$ according to the PDF file No. 65-2901.

The results shown in Figure 4 are consistent with literature reports [32,33] where different synthesis methods of the $\mathrm{NiSb}_{2} \mathrm{O}_{6}$ 's crystalline phase were employed, like the solid-state reaction [31] and the colloidal method [34]. In this work, an economical and simple to implement alternative, a wet-chemistry process, was used successfully. It was possible to obtain with its particle sizes less than $100 \mathrm{~nm}$.

\subsection{SEM Analysis}

Figure 5 shows three typical photomicrographs of the calcined $\mathrm{NiSb}_{2} \mathrm{O}_{6}$ 's surface at different magnifications: $500 \times, 7000 \times$, and $15000 \times$.
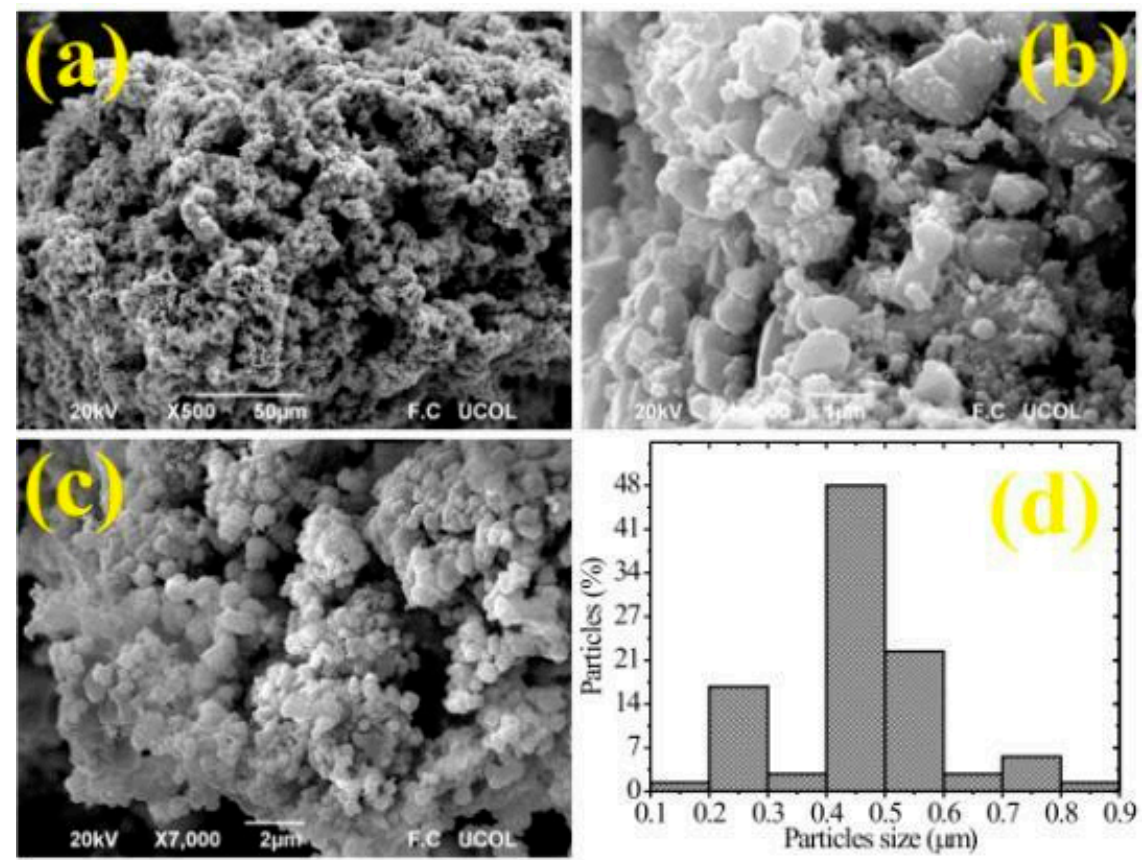

Figure 5. SEM images of the calcined (at $800{ }^{\circ} \mathrm{C}$ ) $\mathrm{NiSb}_{2} \mathrm{O}_{6}$ 's microstructure at magnifications: (a) $500 \times$, (b) $7000 \times$, (c) $15000 \times$, and (d) Particle size distribution.

According to the results shown in Figure $5 \mathrm{a}, \mathrm{b}$, a large agglomeration of differently sized particles can be identified. The morphology of the particles is irregular, showing a rough surface generated by the elimination of organic matter when the material is calcined at $800{ }^{\circ} \mathrm{C}$ (see Figure 5c). Growth and nucleation of this type of morphology can be attributed to the residence time of the material inside the muffle and to the effect of the ethylenediamine used for the preparation of the $\mathrm{NiSb}_{2} \mathrm{O}_{6}$. We have reported in previous works that, by using ethylenediamine during the synthesis process, it was possible to obtain different types of morphologies, like microrods, octahedrons, hexagonal, microplates, and mesoporous-nanoparticles suitable for being used as gas sensors [19,20,22-24,28,29].

The size of the particles was estimated in the range of $0.1-0.9 \mu \mathrm{m}$, with an average of $\sim 0.457 \mu \mathrm{m}$ and a standard deviation of $\pm 0.125 \mu \mathrm{m}$. These results are shown in the form of a histogram of the particle size distribution in Figure $5 \mathrm{~d}$. The porosity on the material's surface is largely due to the release of gases, such as water vapor, $\mathrm{NO}_{\mathrm{x}}$, and $\mathrm{CO}_{2}$ during the heat treatment applied to the material [30].

In general, the ethylenediamine's effect on the production of different morphology types has been thoroughly discussed in previous works [32,33]. The ethylenediamine is incorporated into the inorganic framework and then lost by the heat treatment, thus emerging different types of microstructures [32,33], as occurred in this work. LaMer and Dinegar [35] proposed a mechanism that involves the formation of nanoparticles with different types of morphologies (mainly colloidal dispersions). These authors 
refer that the growth and nucleation of inorganic monodisperse colloidal particles are based on three fundamental stages: The first one states that the concentration of the reactants in the colloidal dispersions increases gradually, the second one establishes that the concentration of the reactants reaches a limit of supersaturation and thus, nucleation occurs rapidly forming the nuclei of the crystals, finally, the third one refers that the growth of the particles occurs, originating their morphology. Agreeing with these authors, the microstructure depicted in Figure 5 can be attributed to the production of stable nuclei formed during the reaction of the reactants when the ethylenediamine is added to the process, giving rise to a colloidal dispersion [19] and, as a consequence, the morphology and the particle sizes shown in this work.

\subsection{Sensing Properties Analysis}

Figure 6 shows the response of the $\mathrm{NiSb}_{2} \mathrm{O}_{6}$ pellets as a function of the $\mathrm{CO}$ concentration at the operating temperatures 100,200 , and $300{ }^{\circ} \mathrm{C}$. It can be clearly verified in the graph that the pellets are sensitive to the concentrations of the gas. The high response of the material is closely related to the chemical adsorption of the gas on the pellets' surface, as well as to the increase of the test gases' concentration and of the temperature. This is corroborated in Figure 6 since as the concentration of the gas and the operating temperature increase, the efficiency of the pellets to detect the $\mathrm{CO}$ concentrations improves substantially. The results obtained in the gas are attributed to the fact that the increase in the operating temperature favors the reaction kinetics between the surface of the pellets and the test gas [20], contributing to a higher oxygen desorption during the adsorption of the test gas [20,22,24,30], which leads to changes in the material's electrical resistance and, consequently, on the high response obtained during the detection tests. The adsorption of different types of oxygen species at high temperatures has been reported in the literature [36]. It can be seen in Figure 6 that the maximum sensitivity magnitudes, $\sim 0.05$ and $\sim 0.35$, were respectively obtained at 200 and $300^{\circ} \mathrm{C}$ for a carbon monoxide concentration of $300 \mathrm{ppm}$.

The response of the $\mathrm{NiSb}_{2} \mathrm{O}_{6}$ pellets is associated to the mechanism of oxygen desorption at high temperatures [36], which implies that at a temperature lower than $150{ }^{\circ} \mathrm{C}$, the thermal energy is not enough to provoke the oxygen desorption reactions so that no electrical response occurs regardless of the gas concentration. In general, the most abundant oxygen species at temperatures below $150{ }^{\circ} \mathrm{C}$ are the $\mathrm{O}_{2}^{-}$ions. Above $150{ }^{\circ} \mathrm{C}$ (in our case $300{ }^{\circ} \mathrm{C}$ ) the formation of oxygen species such as the $\mathrm{O}^{-}$ and $\mathrm{O}^{2-}$ ions takes place, which are more reactive $[22,24,28,30,36]$. Furthermore, the increase of the temperature causes a rise in the solid-gas interactions [19,22,30], leading to a good material's response in $\mathrm{CO}$ atmospheres.

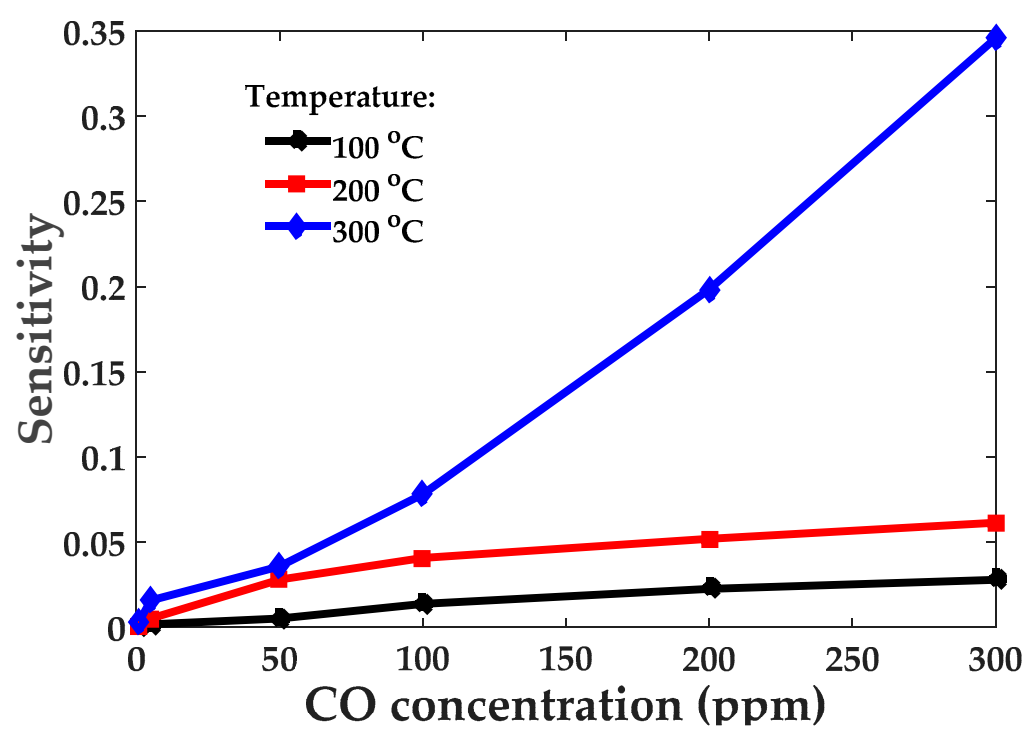

Figure 6. Response of $\mathrm{NiSb}_{2} \mathrm{O}_{6}$ pellets as a function of (a) $\mathrm{CO}$ and concentrations. 
In order to know the variations of the electrical response (resistivity) in the presence of different carbon monoxide (CO) concentrations, the changes in the resistivity were estimated as a function of the gas concentration and the operating temperature. The calculation was made with the formula [20,37]: $\rho=R A / t$, where $R$ is the electrical resistance in the test gases, A is the area of the cross-section, and $t$ is the thickness of the pellets $(=0.5 \mathrm{~mm}$, diameter $=12 \mathrm{~mm})$. The results are shown in Figure 7 .
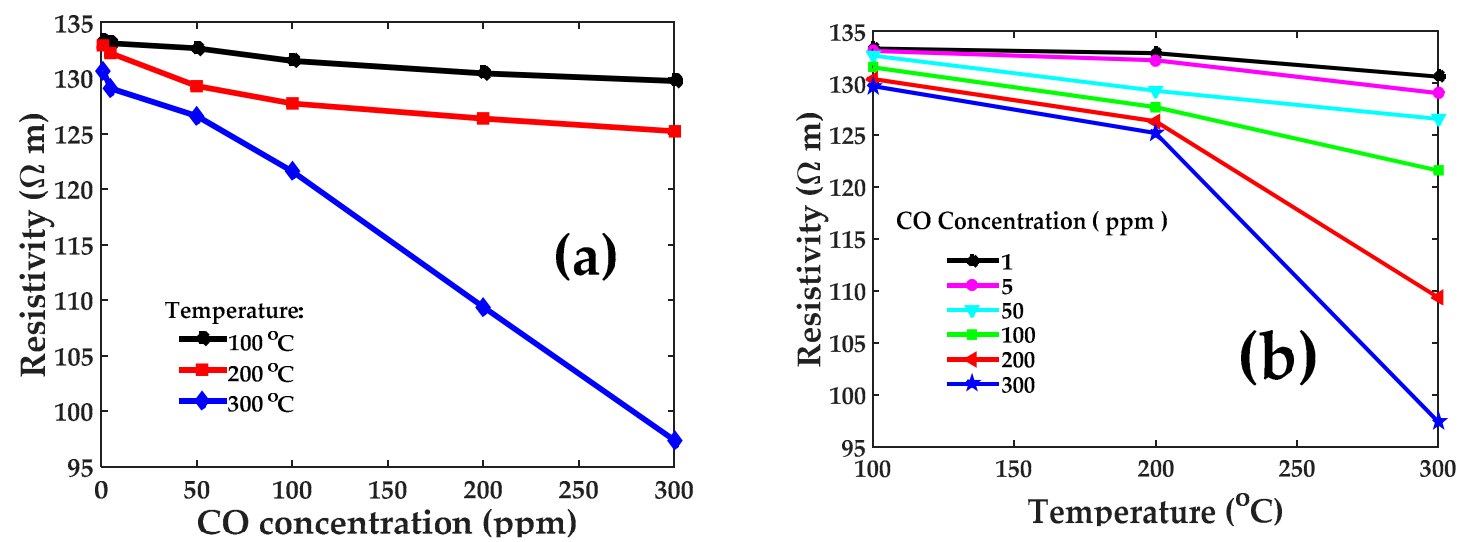

Figure 7. Electrical response (resistivity) of $\mathrm{NiSb}_{2} \mathrm{O}_{6}$ pellets as a function of (a) $\mathrm{CO}$ concentration, (b) $\mathrm{CO}$ operating temperature.

According to the results, the electrical resistivity of the material in $\mathrm{CO}$ atmospheres decays as the concentration and the operating temperature increase. This means that the electrical conductivity of the material increases proportionally as the resistivity decreases (see Figure 7a,b). This behavior is mainly attributed to the fact that, due to the increase of temperature, the charge carriers show more mobility on the surface of the pellets, leading to an increase in the conductivity [20,24]. In addition, it is evident that increasing the concentration of the test gases and the operating temperature, it favors the decrease in resistivity. This phenomenon occurs because the kinetic activity of the gas molecules on the pellets' surface is increased by the rise in operating temperature [24] (in our case at 200 and $300{ }^{\circ} \mathrm{C}$ ). It has been reported in the literature that the temperature and the geometric shape of the sensor (i.e., pellets or films) plays a quite important role in the chemical interaction between the test gases and the chemisorbed oxygen on the material's surface $[20,24,38,39]$, contributing to producing changes in the electrical resistivity, as shown in Figure 7a,b. This trend is typical of a semiconductor material like the one studied in this work $[20,24,37,38,40]$.

Performing the test on a particle at $300^{\circ} \mathrm{C}$, the resistivity of the material was high, with an almost linear trend regardless of the $\mathrm{CO}$ concentrations. However, by increasing the operating temperature to $200{ }^{\circ} \mathrm{C}$, the conductivity increased, and the resistivity decreased. In the case of the oxide pellets, they showed inflection points at $200{ }^{\circ} \mathrm{C}$ for both the $\mathrm{CO}$ atmospheres (see Figure $7 \mathrm{~b}$ ). The resistivity inflection points shown by the pellets at this temperature are clear indications of the transition that the material undergoes due to the increase in the operating temperature of the sensor. On the other hand, at $300{ }^{\circ} \mathrm{C}$, the resistivity in the atmospheres decreased significantly, where the minimum value of resistivity in carbon monoxide was of $94.0 \Omega \mathrm{m}$ at $300 \mathrm{ppm}$. Considering the results shown in Figure $7 \mathrm{a}, \mathrm{b}$, the high response is attributed mainly to the nanometric size obtained during the synthesis process of the oxide. Recent reports have shown that by reducing the particle size of semiconductors, the area-to-volume ratio considerably increases thus favoring high gas adsorption on the surface of the material $[30,40,41]$, leading to a high response in different types of gases.

\subsection{Resistance vs. CO Concentration}

From Figure $7 \mathrm{a}$, the electrical resistance has been calculated for our chemical sensor through Equation $\mathrm{R}=\rho \mathrm{t} / \mathrm{A}$, and then, the behavior of resistance vs. CO concentration can be estimated and graphed as Figure 8 illustrates. 


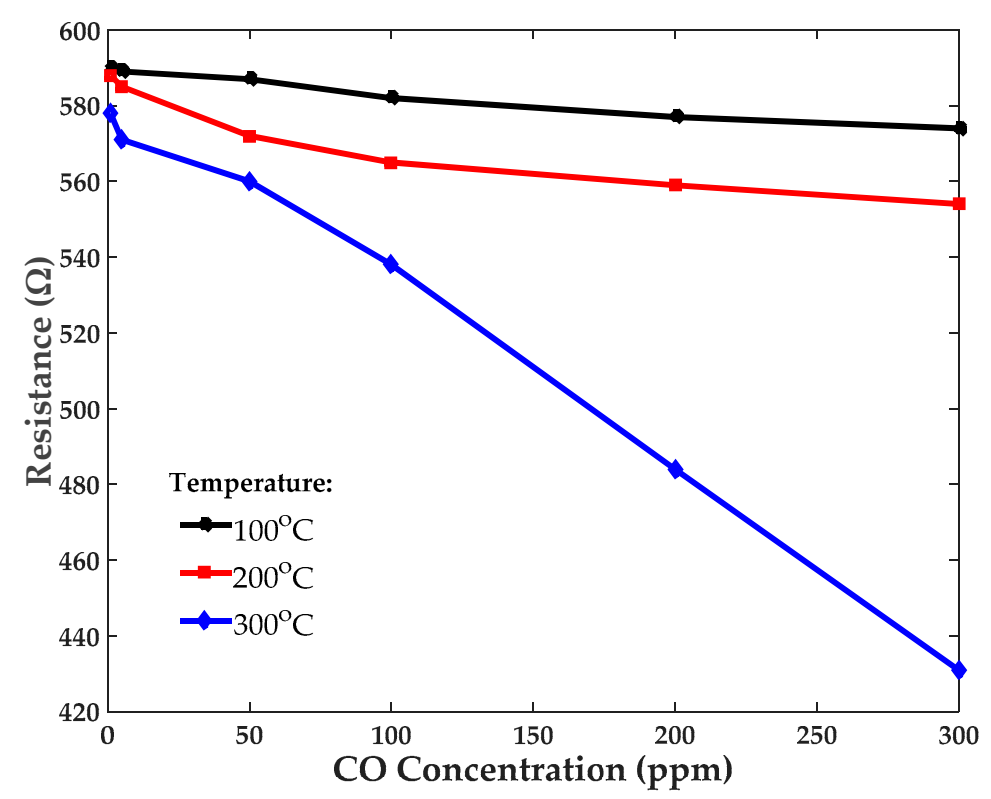

Figure 8. Response of $\mathrm{NiSb}_{2} \mathrm{O}_{6}$ pellets: Resistance vs. $\mathrm{CO}$ concentrations.

Observing Figure 8, when the chemical sensor and $\mathrm{CO}$ gas make a reaction, the resistance decays for three temperatures, 100,200 and $300^{\circ} \mathrm{C}$. The sensor has the highest resistance if both temperatures are 100 and $200{ }^{\circ} \mathrm{C}$. However, when the temperature is $300^{\circ} \mathrm{C}$, sensor's resistance is lower, its decline is major but the sensor has more sensitivity. As a consequence, the operating sensor is better at $300{ }^{\circ} \mathrm{C}$ when the sensor's resistance is into the interval of $578 \Omega$ and $431 \Omega$.

\subsection{CO Detection Circuit}

Based on Figures 3, 7a and 8, a new CO detection system would be implemented using the $\mathrm{NiSb}_{2} \mathrm{O}_{6}$ pellets and a DC electronic circuit. Its characteristics are: its operating concentration is into the interval of 5 and $300 \mathrm{ppm}$, its operating temperatures are $100{ }^{\circ} \mathrm{C}, 20{ }^{\circ} \mathrm{C}$, and $300{ }^{\circ} \mathrm{C}$, high sensitivity at $300{ }^{\circ} \mathrm{C}$, economic fabrication and easy implementation. To operate the $\mathrm{CO}$ detection system at $300{ }^{\circ} \mathrm{C}$ and $50 \mathrm{ppm}$ (or major), we propose the electronic circuit as Figure 9 illustrates.

Observing Figure $9, R_{1}, R_{2}, R_{3}, R_{4}, R_{5}$, and $R_{6}$ have values of $1 \mathrm{~K} \Omega(1000 \Omega)$, the sensor's resistance $R_{S}$ was measured to $\sim 560 \Omega$ (Figure 8 ) and consequently, resistance $R_{x}$ was calibrated to $\sim 560 \Omega$ (Equation (5)). The Wheatstone bridge is supplied by $V_{c c 1} \approx 5 \mathrm{~V}$. Both operational amplifiers are supplied by $\pm V_{c c}= \pm 12 \mathrm{~V}$. The differential amplifier has unitary amplification. Finally, the comparator has its gain in the operational amplifier in an open loop, $A_{o l}=10,000$ (see Equation (10)).

On the other hand, Figure 10 shows the electronic diagram of our DC supply voltage. The voltage source has an error of $\pm 0.2 \mathrm{~V}$, high repeatability, low cost, and good precision. In the power supply, the transformer reduces the alternate current (AC) from $120 \mathrm{~V}$ to $18 \mathrm{~V}$, the bridge diode transforms the alternate current (AC) to direct current (DC), the capacitors filter the electrical signal and devices, LM317 T, LM7812, and LM7912 regulate the current voltages, $V_{c c 1} \approx 5 \mathrm{~V}$ and $\pm V_{c c}= \pm 12 \mathrm{~V}$. Notice that, $V_{c c 1}$ has a fine-tuning through the resistor $R_{A F}$. 


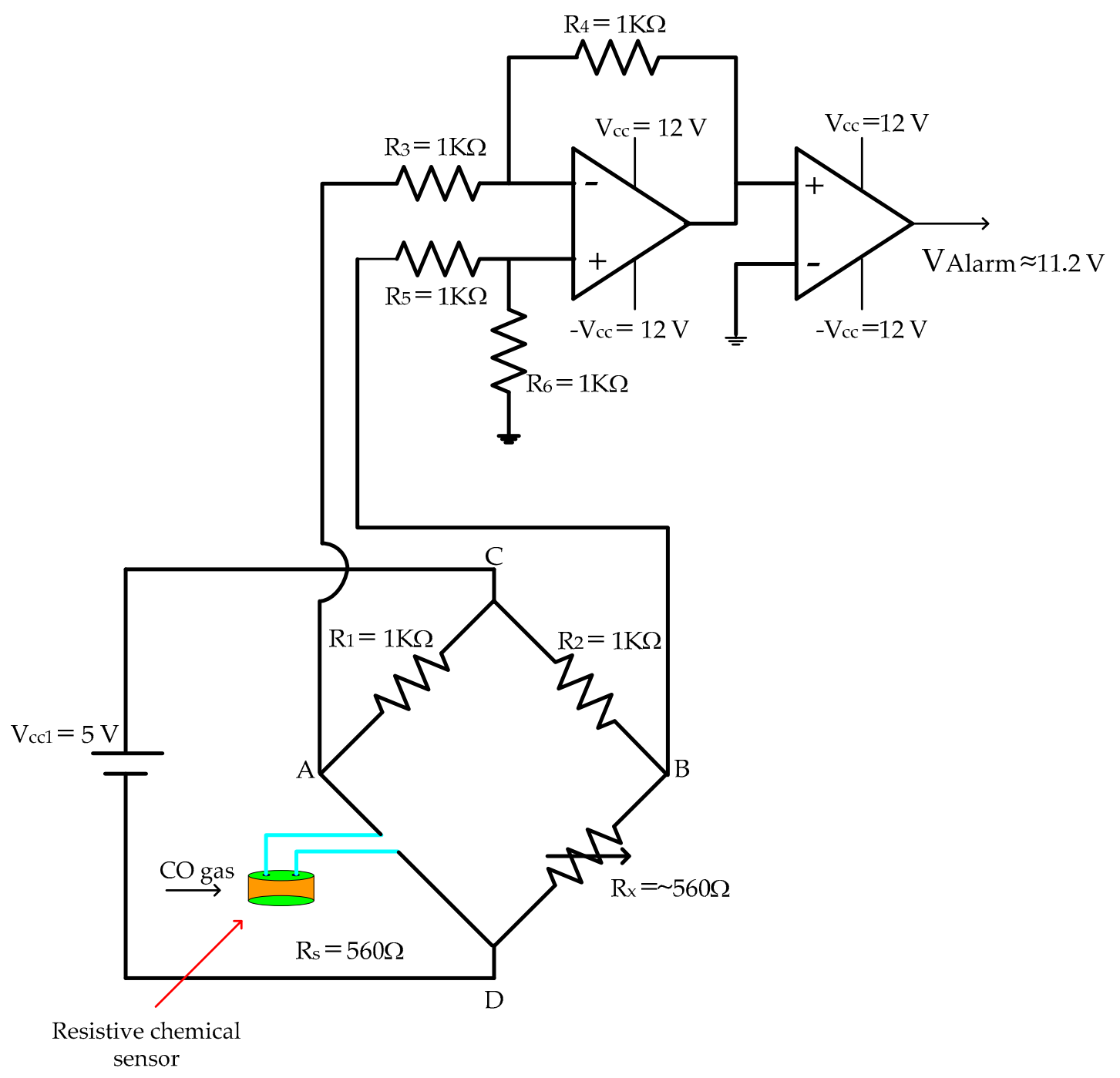

Figure 9. A CO detection system proposed at $300{ }^{\circ} \mathrm{C}$ and $50 \mathrm{ppm}$ (or higher). 


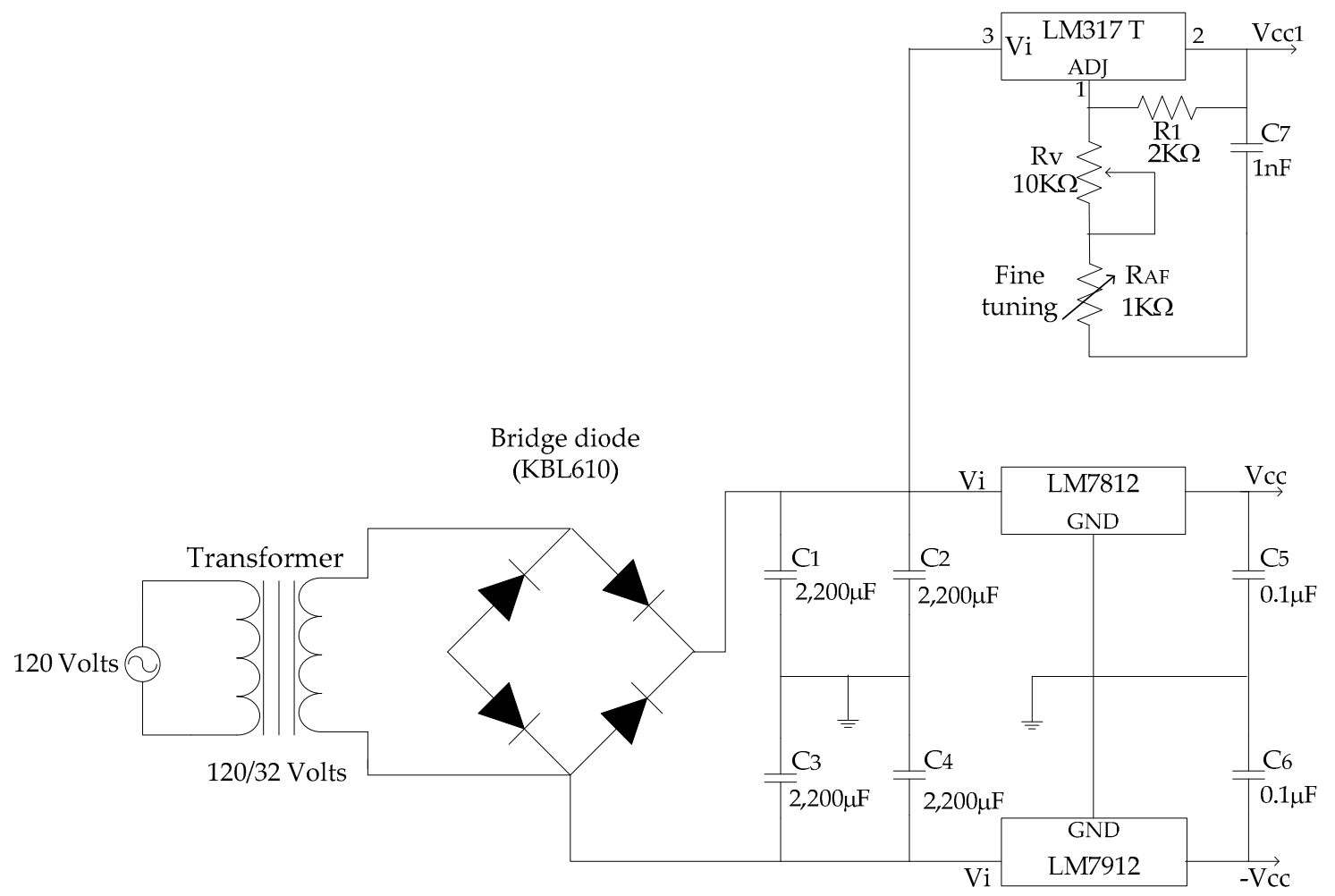

Figure 10. Electronic diagram of our DC supply voltage.

\subsection{CO Detection Device}

Figure 11 shows our $\mathrm{CO}$ detection device. For its construction, the electronic circuit which was shown in Figure 9 and the DC supply source shown in Figure 10 were considered. The Printed Circuit Board ( $\mathrm{PBC}$ ) was designed using the CAD Altium design program, version 17. Finally, the required materials were: a transformer 120:24 Volts, a diode bridge KBL610 (3A), seven capacitors $\left(C_{1}=C_{2},=C_{3}=C_{4}=2200 \mu \mathrm{F}(50 \mathrm{~V}), C_{5}=C_{6}=0.1 \mu \mathrm{F}, C_{7}=1 \mathrm{nF}\right)$, seven precision resistors $\left(R_{1}=R_{2}=R_{3}=R_{4}=R_{5}=R_{6}=I \mathrm{~K} \Omega, R_{7}=2 \mathrm{~K} \Omega\right)$, a potentiometer $\left(R_{v}=10 \mathrm{~K} \Omega\right)$, four rectangular cermet trimmer potentiometers $\left(R_{x}=1 \mathrm{~K} \Omega, R_{A F}=1 \mathrm{~K} \Omega, R_{G 1}=10 \mathrm{~K} \Omega, R_{\mathrm{G} 2}=10 \mathrm{~K} \Omega\right)$, a TL084 (3 V to $32 \mathrm{~V}$, DIP, 14 Pines), a phenolic one side plate $(15 \mathrm{~cm} \times 15 \mathrm{~cm})$, three screw connectors, an LM317T (regulator to $5 \mathrm{~V}$ ), an LM7812 (regulator to $12 \mathrm{~V}$ ), and an LM7912 (Regulator to $-12 \mathrm{~V}$ ).

In the CO detection device, the sensitivity was increased collocating two resistors, $R_{G 1}$ and $R_{G 2}$. That is possible because $R_{4}$ and $R_{G 1}$ were connected using a serial array whereas $R_{6}$ and $R_{G 2}$ were also connected to applying a serial array. Therefore, Equation (8) is satisfied if and only if $R_{G 1}=R_{G 2}$. The output voltage $V_{o}$ will be

$$
V_{o}=A_{m}\left(V_{B}-V_{A}\right)
$$

where the modified amplification is given by $A_{m}=\frac{R_{4}+R_{G 1}}{R_{3}}=\frac{R_{6}+R_{G 2}}{R_{5}}$ and its value can only be between 1 and 11.

On the other hand, the device operates as Figure 12 illustrates. If $\mathrm{CO}$ concentration is equal or greater than $50 \mathrm{ppm}$, the sensor's resistance diminishes and as a consequence, the Wheatstone bridge is unbalanced, provoking the signal alarm $V_{\text {Alarm }} \approx 11.2 \mathrm{~V}$ (Alarm state "On"). However, if CO concentration is lower than 50ppm, the Equation (6) is not satisfied and then the signal alarm is close to zero, $V_{\text {Alarm }} \approx 0 \mathrm{~V}$ (Alarm state "Off"). For our new toxic gas detector device, the thresholding value can be selected through $R_{x}$ : if $R_{x}>560 \Omega$ then the device will detect CO concentrations lower than $50 \mathrm{ppm}$ (or higher) but if $R_{x}<560 \Omega$ then the device will detect $\mathrm{CO}$ concentrations greater than $50 \mathrm{ppm}$. 


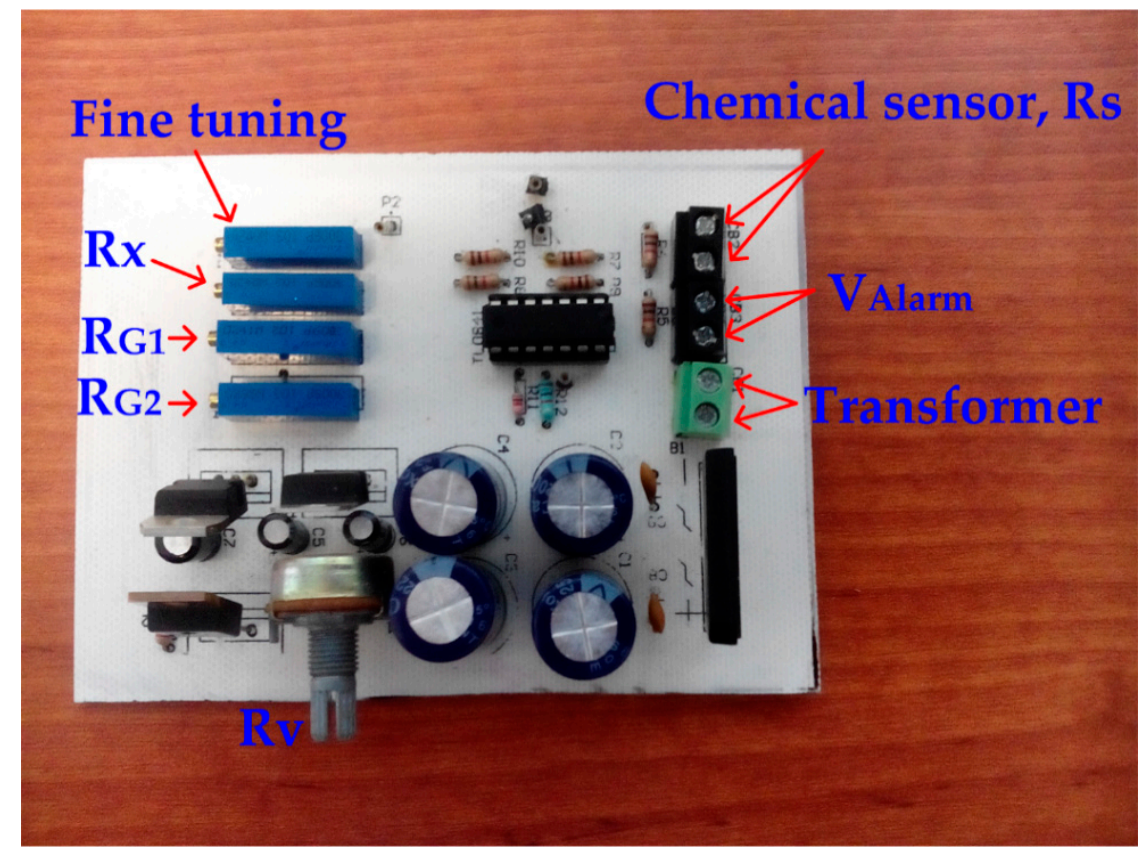

Figure 11. CO detection device built and its electronic elements.

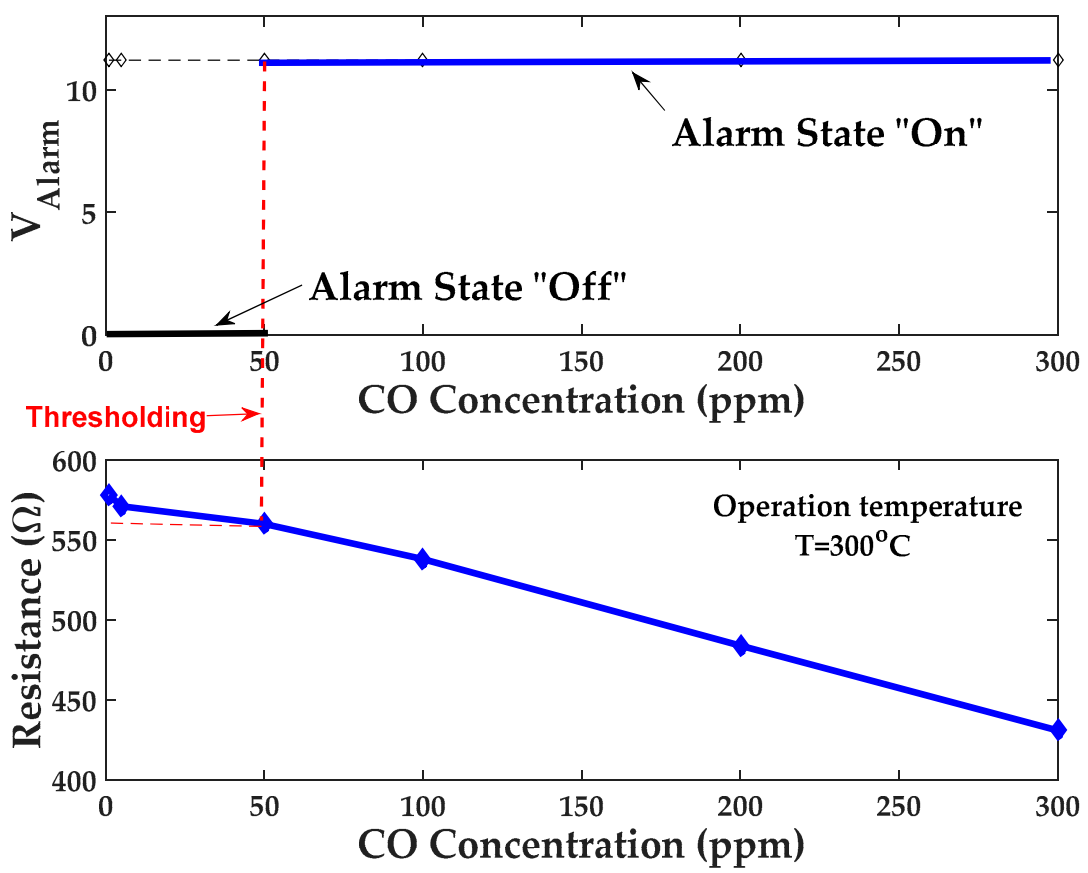

Figure 12. Signals measured with our $\mathrm{CO}$ detection device (operating temperature to $50 \mathrm{ppm}$ and $\left.\mathrm{T}=300^{\circ} \mathrm{C}\right)$.

\section{Discussion}

Based on the experimental results, a new prototype was proposed, developed, and applied for $\mathrm{CO}$ gas detection. The prototype device consisted of a chemical sensor and a DC electronic circuit. The chemical sensor was made using the nickel antimonate oxide. The oxide was synthetized by means of an alternative microwave-assisted wet-chemistry process, using nickel nitrate, antimony chloride, ethylenediamine, and ethyl alcohol. The precursor material was dried at $200{ }^{\circ} \mathrm{C}$ and later calcined at $800^{\circ} \mathrm{C}$ in static air. The crystalline phase of the calcined material was analyzed by $\mathrm{X}$-ray diffraction, finding the cell parameters $\mathrm{a}=\mathrm{b}=4.641 \AA$ and $\mathrm{c}=9.219 \AA$, and spatial group $\mathrm{P} 4_{2} / \mathrm{mnm}$ 
(136). Their sensitivity tests were developed applying static tests (Direct current, DC), an excellent electrical response was obtained. For its signal adaptation a DC electronic circuit was built which was based on a Wheatstone bridge, a DC source, a differential amplifier, and an operational amplifier comparator. That electronic circuit was implemented on a PBC of size $15 \mathrm{~cm} \times 15 \mathrm{~cm}$.

The CO detection device has good characteristics: low cost, high sensitivity, good performance, fast response, selective sensitivity (through trimmer potentiometers), adaptability, $\mathrm{CO}$ concentration detected into the interval of 1 to $300 \mathrm{ppm}$, operating temperatures 100,200 , and $300{ }^{\circ} \mathrm{C}$, optimal operating temperature at $300{ }^{\circ} \mathrm{C}$, its dimension $(15 \mathrm{~cm} \times 15 \mathrm{~cm})$, AC supply voltage $(120 \mathrm{~V})$ and DC output voltage $(11.2 \mathrm{~V})$. However, such characteristics can be improved using better technology for its implementation.

In reference [42], the authors proposed a $\mathrm{CO}_{2}$ detection system based on $\mathrm{CoSb}_{2} \mathrm{O}_{6}$ oxide. For its signal adaptation, the impedance response was analyzed. From the analysis, an electronic circuit was proposed. Its implementation had high complexity because the signal analysis was done on the s-plane, and the electronic circuit was based on the impedance. In this work, another chemical sensor was applied for the CO gas detection but its signal adaptation was made based on the direct current, simplifying the analysis and its implementation. Therefore, comparing both proposals, our proposal reduced complexity, analysis, cost, materials, electronic components and optimized the performance.

The $\mathrm{CO}$ detection device finds practical safety applications where $\mathrm{CO}$ detection is desirable. Some examples are boiler safety system, locked chimneys, inverted fireplace effect, corroded ventilation pipes and more. Therefore, our future work is in the following direction: CO detector applications, the detector device would be optimized through digital electronics and the nickel antimonate $\left(\mathrm{NiSb}_{2} \mathrm{O}_{6}\right)$ oxide would be applied for the propane $\left(\mathrm{C}_{3} \mathrm{H}_{8}\right)$ gas detection.

\section{Conclusions}

We have employed a wet-chemistry synthesis process for producing particles of nanometric size ( $\sim 23.24 \mathrm{~nm}$ on average) for their application in gas detection. This preparation method is economical and very efficient to obtain different morphologies. Furthermore, it is possible to obtain the crystalline phase at relatively low temperatures compared to traditional methods such as the solid-state reaction with this process. The $\mathrm{NiSb}_{2} \mathrm{O}_{6}$ nanoparticles showed high sensitivity in carbon monoxide (CO) atmospheres at different operating temperatures $\left(100,200\right.$, and $\left.300^{\circ} \mathrm{C}\right)$. The optimum performance of the oxide was at concentrations of $300 \mathrm{ppm}$ of $\mathrm{CO}$ at $300^{\circ} \mathrm{C}$. The maximum value of the sensitivity was of $\sim 0.35$ in CO. Based on these results, a new prototype device was implemented for $\mathrm{CO}$ gas detection. Its operating concentration was into the interval of 1 to $300 \mathrm{ppm}$. Its operating temperatures were 100, 200 and $300^{\circ} \mathrm{C}$. However, its optimal operation was at $300^{\circ} \mathrm{C}$.

The $\mathrm{CO}$ detection device was built using analogic electronics: a Wheatstone bridge and electronic circuits based on operational amplifiers. The device had good performance, fast response, selective sensitivity, adaptability, and low cost. Our prototype device finds practical application where it is desirable to detect carbon monoxide leaks.

Author Contributions: A.G.B. and J.A.R.O. synthetized the $\mathrm{NiSb}_{2} \mathrm{O}_{6}$ Oxide Powders; H.G.B., V.M.R.B., L.G.O., O.B.A. developed the Physical characterization of $\mathrm{NiSb}_{2} \mathrm{O}_{6}$ Powders; J.T.G.B., A.C.Z., M.E.S.M. developed the signal analysis and proposed the electronic circuit. All authors wrote the paper.

Funding: This research received no external funding.

Acknowledgments: The authors thank the Mexico's National Council of Science and Technology (CONACyT) for the support granted. Antonio Casillas Zamora expresses his gratitude to CONACyT for his scholarship. This investigation was carried out following the line of research "Nanostructured Semiconductor Oxides" of the academic group UDG-CA-895 "Nanostructured Semiconductors" of CUCEI, University of Guadalajara. Likewise, we thank Sergio Oliva-León, Miguel-Ángel Luna-Arias, M. L. Olvera-Amador, for their technical assistance.

Conflicts of Interest: The authors declare no conflict of interest. 


\section{References}

1. Wetchakun, K.; Samerjai, T.; Tamaekong, N.; Liewhiran, C.; Siriwong, C.; Kruefu, V.; Wisitsoraat, A.; Tuantranont, A.; Phanichphant, S. Semiconducting metal oxides as sensors for environmentally hazardous gases. Sens. Actuators B 2011, 160, 580-591. [CrossRef]

2. Niu, X.; Du, W.; Du, W. Preparation and gas sensing properties of $\mathrm{ZnM}_{2} \mathrm{O}_{4}(\mathrm{M} .=\mathrm{Fe}, \mathrm{Co}, \mathrm{Cr})$. Sens. Actuators B 2004, 99, 405-409. [CrossRef]

3. Navarro-Botella, P.; García-Aguilar, J.; Berenguer-Murcia, A.; Cazorla-Amorós, D. Pd and Cu-Pd nanoparticles supported on multiwall carbon nanotubes for $\mathrm{H}_{2}$ detection. Mater. Res. Bull. 2017, 93, 102-111. [CrossRef]

4. Fleischer, M.; Meixner, H. Fast gas sensors based on metal oxides which are stable at high temperatures. Sens. Actuators B 1997, 43, 1-10. [CrossRef]

5. Fiels, L.L.; Zheng, J.P.; Cheng, Y.; Xiong, P. Room-temperature low-power hydrogen sensor based on a single tin dioxide nanobelt. Appl. Phys. Lett. 2006, 88, 263102. [CrossRef]

6. Yoon, J.W.; Grilli, M.L.; Di Bartolomeo, E.; Polini, R.; Traversa, E. The $\mathrm{NO}_{2}$ response of solid electrolyte sensors made using nano-sized $\mathrm{LaFeO}_{3}$ electrodes. Sens. Actuators B 2001, 76, 483-488. [CrossRef]

7. Makri, A.; Stilianakis, N.I. Vulnerability to Air Pollution Health Effects. Int. J. Hyg. Environ. Health 2008, 211, 326-336. [CrossRef]

8. Zuidema, T.; Nentjes, A. Health Damage of Air Pollution: An Estimate of a Dose Response Relationship for the Netherlands. Environ. Resour. Econ. 2007, 9, 291-308. [CrossRef]

9. Brunekreef, B.; Holgate, S.T. Air pollution and health. Lancet 2002, 360, 1233-1242. [CrossRef]

10. Sukunta, J.; Wisitsoraat, A.; Tuantranont, A.; Phanichphant, S.; Liewhiran, C. Highly-sensitive $\mathrm{H}_{2} \mathrm{~S}$ sensors based on flame-made V-substituted $\mathrm{SnO}_{2}$ sensing films. Sens. Actuators B 2017, 242, 1095-1107. [CrossRef]

11. Afzal, A.; Cioffi, N.; Sabbatini, L.; Torsi, L. NOx sensors based on semiconducting metal oxide nanostructures: Progress and perspectives. Sens. Actuators B 2012, 171-172, 25-42. [CrossRef]

12. Kanazawa, E.; Sakai, G.; Shimanoe, K.; Kanmura, Y.; Teraoka, Y.; Miura, N.; Yamazoe, N. Metal oxide semiconductor $\mathrm{N}_{2} \mathrm{O}$ sensor for medical use. Sens. Actuators B 2001, 77, 72-77. [CrossRef]

13. Addabbo, T.; Bertocci, F.; Fort, A.; Gregorkiewitz, M.; Mugnaini, M.; Spinicci, R.; Vignoli, V. Gas sensing properties and modeling of $\mathrm{YCoO}_{3}$ based perovskite materials. Sens. Actuators B 2015, 221, 1137-1155. [CrossRef]

14. Yuan, Y.; Wang, B.; Wang, C.; Li, X.; Huang, J.; Zhang, H.; Xia, F.; Xiao, J. Effects of $\mathrm{CoFe}_{2} \mathrm{O}_{4}$ electrode microstructure on the sensing properties for mixed potential $\mathrm{NH}_{3}$. Sens. Actuators B 2017, 239, 462-466. [CrossRef]

15. Zhao, J.; Liu, Y.; Li, X.; Lu, G.; You, L.; Liang, X.; Liu, F.; Zhang, T.; Du, Y. Highly sensitive humidity sensor based on high surface area mesoporous $\mathrm{LaFeO}_{3}$ prepared by a nanocasting route. Sens. Actuators B 2013, 181, 802-809. [CrossRef]

16. Moseley, P.T.; Williams, D.E.; Norris, J.O.W.; Tofield, B.C. Electrical conductivity and gas sensitivity of some transition metal tantalates. Sens. Actuators 1988, 14, 79-91. [CrossRef]

17. Wang, B.; Yu, Q.; Zhang, S.; Wang, T.; Sun, P.; Chuai, X.; Lu, G. Gas sensing with yolk-shell LaFeO3 microspheres prepared by facile hydrothermal synthesis. Sens. Actuators B 2018, 258, 1215-1222. [CrossRef]

18. Yang, X.; Zhang, S.; Yu, Q.; Sun, P.; Liu, F.; Lu, H.; Yan, X.; Zhou, X.; Liang, X.; Gao, Y.; et al. Solvothermal synthesis of porous $\mathrm{CuFe}_{2} \mathrm{O}_{4}$ nanospheres for high performance acetone sensor. Sens. Actuators B 2018, 270, 538-544. [CrossRef]

19. Guillén-Bonilla, H.; Gildo-Ortiz, L.; Olvera-Amador, M.D.L.L.; Santoyo-Salazar, J.; Rodríguez-Betancourtt, V.M.; Guillen-Bonilla, A.; Reyes-Gómez, J. Sensitivity of Mesoporous $\mathrm{CoSb}_{2} \mathrm{O}_{6}$ Nanoparticles to Gaseous CO and $\mathrm{C}_{3} \mathrm{H}_{8}$ at Low Temperatures. J. Nanomater. 2015, 2015, 308465. [CrossRef]

20. Guillén-Bonilla, A.; Rodríguez-Betancourtt, V.M.; Guillén-Bonilla, J.T.; Sánchez-Martínez, A.; Gildo-Ortiz, L.; Santoyo-Salazar, J.; Morán-Lázaro, J.P.; Guillén-Bonilla, H.; Blanco-Alonso, O. A novel CO and $\mathrm{C}_{3} \mathrm{H}_{8}$ sensor made of $\mathrm{CuSb}_{2} \mathrm{O}_{6}$ nanoparticles. Ceram. Int. 2017, 43, 13635-13644. [CrossRef]

21. Singh, A.; Singh, A.; Singh, S.; Tandon, P. Nickel antimony oxide $\left(\mathrm{NiSb}_{2} \mathrm{O}_{6}\right)$ A fascinating nanostructured material for gas sensing application. Chem. Phys. Lett. 2016, 646, 41-46. [CrossRef] 
22. Guillén-Bonilla, H.; Flores-Martínez, M.; Rodríguez-Betancourtt, V.M.; Guillen-Bonilla, A.; Reyes-Gómez, J.; Gildo-Ortiz, L.; Olvera-Amador, M.D.L.L.; Santoyo-Salazar, J. A Novel Gas Sensor Based on $\mathrm{MgSb}_{2} \mathrm{O}_{6}$ Nanorods to Indicate Variations in Carbon Monoxide and Propane Concentrations. Sensors 2016, 16, 177. [CrossRef] [PubMed]

23. Guillen-Bonilla, H.; Rodríguez-Betancourtt, V.M.; Guillén-Bonilla, J.T.; Reyes-Gómez, J.; Gildo-Ortiz, L.; Flores-Martínez, M.; Olvera-Amador, M.D.L.L.; Santoyo-Salazar, J. $\mathrm{CO}$ and $\mathrm{C}_{3} \mathrm{H}_{8}$ Sensitivity Behavior of Zinc Antimonate Prepared by a Microwave-Assisted Solution Method. J. Nanomater. 2015, 2015, 979543. [CrossRef]

24. Guillen-Bonilla, A.; Blanco-Alonso, O.; Guillen-Bonilla, J.T.; Olvera-Amador, M.D.L.L.; Rodríguez-Betancourtt, V.M.; Sánchez-Martínez, A.; Moran-Lázaro, J.P.; Martínez-García, M.; Guillen-Bonilla, H. Synthesis and characterization of cobalt antimonate nanostructures and their study as potential $\mathrm{CO}$ and $\mathrm{CO}_{2}$ sensor at low temperatures. J. Mater. Sci. Mater. Electron. 2018, 29, 15632-15642. [CrossRef]

25. Montero, M.; Molina, T.; Szafran, M.; Moreno, R.; Nieto, M.I. Alumina porous nanomaterials obtained by colloidal processing using D-fructose as dispersant and porosity promoter. Ceram. Int. 2012, 38, 2779-2784. [CrossRef]

26. Lee, S.J.; Kriven, W.M. Crystallization and Densification of Nano-Size Amorphous Cordierite Powder Prepared by a PVA Solution-Polymerization Route. J. Am. Ceram. Soc. 1998, 81, 2605-2612. [CrossRef]

27. Seung-Man, Y.; Shin-Hyun, K.; Jong-Min, L.; Gi-Ra, Y. Synthesis and assembly of structured colloidal particles. J. Mater. Chem. 2008, 18, 2177-2190.

28. Rodríguez Betancourtt, V.M.; Guillen Bonilla, H.; Flores Martínez, M.; Guillen Bonilla, A.; Moran Lazaro, J.P.; Guillen Bonilla, J.T.; González, M.A.; Olvera Amador, M.D.L.L. Gas Sensing Properties of $\mathrm{NiSb}_{2} \mathrm{O}_{6}$ Micro-and Nanoparticles in Propane and Carbon Monoxide Atmospheres. Hindawi J. Nanomater. 2017, 2017, 8792567. [CrossRef]

29. Guillen Bonilla, H.; Olvera Amador, M.D.L.L.; Casallas Moreno, Y.L.; Guillen Bonilla, J.T.; Guillen Bonilla, A.; Gildo Ortiz, L.; Morán Lázaro, J.P.; Santoyo Salazar, J.; Rodríguez Betancourtt, V.M. Synthesis and characterization of nickel antimonate nanoparticles: Sensing properties in propane and carbon monoxide. J. Mater. Sci. Mater. Electron. 2019, 30,6166-6177. [CrossRef]

30. Gildo-Ortiz, L.; Guillén-Bonilla, H.; Santoyo-Salazar, J.; Olvera-Amador, M.L.; Karthik, T.V.K.; Campos-González, E.; Reyes-Gómez, J. Low-temperature synthesis and gas sensitivity of perovskite-type $\mathrm{LaCoO}_{3}$ nanoparticles. J. Nanomater. 2014, 2014, 164380. [CrossRef]

31. Ehrenberg, H.; Wltschek, G.; Rodriguez-Carvajal, J.; Vogt, T. Magnetic structures of the tri-rutiles $\mathrm{NiTa}_{2} \mathrm{O}_{6}$ and $\mathrm{NiSb}_{2} \mathrm{O}_{6}$. J. Magn. Magn. Mater. 1998, 184, 111-115. [CrossRef]

32. Deng, Z.X.; Wang, C.; Sun, X.M.; Li, Y.D. Structure-directing coordination template effect of ethylenediamine in formations of $\mathrm{ZnS}$ and $\mathrm{ZnSe}$ nanocrystallites via solvothermal route. Inorg. Chem. 2002, 41, 869-873. [CrossRef] [PubMed]

33. Wang, X.; Li, Y. Solution-based synthetic strategies for 1-D nanostructures. Inorg. Chem. 2006, 45, 7522-7534. [CrossRef] [PubMed]

34. Han, J.; Xu, M.; Jia, M.; Liu, T. Evaluation of reduced grapheme oxide-supported NiSb2O6 nanocomposites for reversible lithium storage. Ceram. Int. 2016, 42, 14782-14787. [CrossRef]

35. Lamer, V.K.; Dinegar, R.H. Theory, production and mechanism of formation of monodispersed hydrosols. J. Am. Chem. Soc. 1950, 72, 4847-4854. [CrossRef]

36. Shih-Chia, C. Oxygen chemisorption on tin oxide: Correlation between electrical conductivity and EPR measurements. J. Vac. Sci. Technol. 1979, 17, 366-369.

37. Kita, J.; Engelbrecht, A.; Schubert, F.; Gro, A.; Rettigand, F.; Moos, R. Some practical points to consider with respect to thermal conductivity and electrical resistivity of ceramic substrates for high-temperature gas sensors. Sens. Actuators B 2015, 213, 541-546. [CrossRef]

38. McAleer, J.F.; Moseley, P.T.; Norris, J.O.W.; Williams, D.E. Tin dioxide gas sensors: Part 1.-Aspects of the surface chemistry revealed by electrical conductance variations. J. Chem. Soc. Faraday Trans. 1 1987, 183, 1323-1346. [CrossRef]

39. Mirzaei, A.; Leonardi, S.G.; Neri, G. Detection of hazardous volatile organic compounds (VOCs) by metal oxide nanostructures-based gas sensors: A review. Ceram. Int. 2016, 42, 15119-15141. [CrossRef] 
40. Song, E.; Choi, J.W. Conducting polyaniline nanowire and its applications in chemiresistive sensing. Nanomaterials 2013, 3, 498-523. [CrossRef]

41. Lin, T.; Xin, L.; Li, S.; Wang, Q. The Morphologies of the Semiconductor Oxides and Their Gas-Sensing Properties. Sensors 2017, 17, 2779. [CrossRef] [PubMed]

42. Guillén-Bonilla, A.; Rodríguez-Betancourtt, V.M.; Guillén-Bonilla, H.; Gildo-Ortiz, L.; Blanco-Alonso, O.; Franco-Rodríguez, N.E.; Reyes-Gómez, J.; Casillas-Zamora, A.; Guillen-Bonilla, J.T. A new $\mathrm{CO}_{2}$ detection system based on the trirutile-type $\mathrm{CoSb}_{2} \mathrm{O}_{6}$ oxide. J. Mater. Sci. Mater. Electron. 2018, 29, 15741-15753. [CrossRef]

(C) 2019 by the authors. Licensee MDPI, Basel, Switzerland. This article is an open access article distributed under the terms and conditions of the Creative Commons Attribution (CC BY) license (http://creativecommons.org/licenses/by/4.0/). 